\title{
UM ESTUDO DA GÊNESE DOCUMENTAL DE ÁLBUNS FOTOGRÁFICOS
}

\author{
Cristina Ribeiro Santos (Ciência da Informação - UEL) \\ Lidiane Marques Freitas (Ciência da Informação - UEL) \\ Prof. ${ }^{\mathrm{a}} \mathrm{Dr}^{\mathrm{a}}$ Ana Cristina de Albuquerque (Orientadora)
}

\section{RESUMO}

Os álbuns fotográficos são compostos por materiais dos mais variados tipos e formatos, que entrelaçados formam uma narrativa nem sempre única. Eles permitem o agrupamento de vários tipos de suportes, que seguem desde sua capa até suas páginas finais e que podem conter: bilhetes, papéis, adesivos, cartões, avisos, e recortes de jornais. Formam uma diversidade de sentido, de funções, de leituras e possíveis usos. Mas, também, expõe uma complexidade em sua organização, objetivada pelos usos que este material possa ter, como nas pesquisas históricas e científicas. Assim, a busca por sua gênese, ou seja, sua intenção funcional, usos, acúmulos e sua criação é um caminho para contribuir com a organização e representação de suas imagens. Diante do exposto, o objetivo que norteia este trabalho é levantar na bibliografia existente quais as indicações e características que fazem parte desta busca pela gênese documental do álbum fotográfico. Este processo está atrelado a fase embrionária, durante a seleção e recolhimento do material e se desenvolve durante toda sua formação, agregando valor e se transformando em acervo, e por consequência em patrimônio.

Palavras-Chaves: Álbuns fotográficos, Gênese Documental, Organização e Representação de Imagens Fotográficas.

\section{INTRODUÇÃO}

As discussões que circundam o álbum fotográfico, em especial o mapeamento teórico da Organização e Representação da Informação possui em seu arcabouço teórico elementos como a análise e tematização do conteúdo imagético e textual, indexação, armazenamento e posteriormente a recuperação desta informação.

Estes elementos possuem, ainda, pressupostos básicos para pensar o álbum fotográfico como um documento, um recurso informacional, e principalmente, a relevância e funcionalidade que a gênese documental tem neste domínio. Nesse sentido, este estudo vincula a gênese documental do álbum fotográfico com a Organização e Representação da Informação.

A Organização e Representação da Informação é uma subárea da Ciência da Informação, responsável pela organização e representação de recursos informacionais. Seu principal objetivo é fornecer acesso aos objetos informacionais, que são informações registradas nos mais variados tipos de suporte, como textos, registros sonoros, páginas web, representações cartográficas, imagens, entre outros (LIMA; ALVARES, 2012).

A organização de informações consiste em classificar, descrever, arranjar objetos informacionais com vistas na recuperação da informação, enquanto a representação da informação propõe colocar algum símbolo significativo em lugar de uma informação, ou seja, é um ato de representação, que utiliza de símbolos, palavras, 


\section{SEMINÁRIO DE PESQUISA EM CIÊNCIAS HUMANAS - SEPECH \\ Humanidades, Estado e desafios didático-científicos \\ Londrina, 27 a 29 de julho de 2016}

imagens, desenhos ou qualquer outro elemento significativo para representar uma realidade (ALVARENGA, 2003).

O álbum fotográfico é um objeto complexo e carregado de significação, possui diversos tipos de materiais como: fotográficas, bilhetes, papéis, adesivos, cartões, avisos e até recortes de jornais. Toda essa coletânea de aparatos representam uma intencionalidade de seu (s) originador (es), mesmo de forma natural, a formação de álbum fotográfico expõe fatos, acontecimentos que só são entendidos se vinculados a sua formação embrionária, ou seja a sua gênese documental.

Nesse sentido e como fruto de estudos do projeto de pesquisa de Organização e Representação da Informação e do Conhecimento de Recursos Imagéticos do Departamento de Ciência da Informação da Universidade Estadual de Londrina, que está pesquisa se propôs a levantar na bibliografia existente as indicações e características que fazem parte da busca pela gênese documental do álbum fotográfico.

Trata-se de uma pesquisa de caráter qualificativo, que se utiliza da pesquisa bibliográfica para suscitar uma discussão sobre a importância do conhecimento da origem, da gênese documental do álbum fotográfico na organização, tratamento e representação de seus objetos informacionais, perpassando pela discussão de seu contexto histórico e desenvolvimento.

\section{O ÁLBUM FOTOGRÁFICO: CONTEXTO HISTÓRICO E DESENVOLVIMENTO.}

A origem do álbum fotográfico está atrelada a um dos seus componentes, a fotografia, por meio desta pontuamos sua origem e acumulo nos âmbitos privados e públicos, institucionais e familiares. O álbum de família anuncia-se de outro lado da foto, isolada, "[...] não como tempo instantâneo, inevitável, que consome o sentido da imagem única, mas como tempo historiado e ritualizado, como olhar para o futuro e para observadores específicos familiares sobreviventes". (SILVA, 2008, p.38)

Ao fim desta fronteira no conteúdo, passemos a característica embrionária do álbum fotográfico: a fotografia. Em 1814 quando Joseph Nicéphore Niépce (1765-1833) inicia suas pesquisas sobre a fixação de imagens da câmara escura estava a dar uma continuidade a um processo anterior a este século; o crescente consumo de imagens. E em 1829, Niépce se associa a Louis J. M. Daguerre, acompanhado deste dão continuidade às pesquisas sobre a representação de imagens na câmara escura e a técnica torna-se um fenômeno do consumo imagético, deste e dos séculos que se sucederam.

Tal técnica de registro, aperfeiçoada, mais tarde por Louis J.M. Daguerre (após a morte de Joseph Nicéphore Niépce) é apresentada "A 19 de agosto de 1839, em sessão da Academia de Belas Artes, Arago deu a conhecer publicamente o processo do daguerreotipo [...]"' (SOUGEZ, 2001, p.49).

A Fotografia após esta apresentação tornou-se uma das principais consequências sociais do uso e consumo da invenção que conhecemos como fotografia, é que seus suportes de baixo custo, levaram a proliferação e disseminar dos registros imagéticos da população. Tal acúmulo fora tanto que chegou a um nível que fomentou a gênese de coleções desses registros. Seja pela união das imagens adquiridas e 


\section{SEMINÁRIO DE PESQUISA EM CIÊNCIAS HUMANAS - SEPECH \\ Humanidades, Estado e desafios didático-científicos \\ Londrina, 27 a 29 de julho de 2016}

acumuladas uma a uma, ou os álbuns de temáticas como de lugares exóticos, personagens famosos, eventos entre outros.

Coleções, que ganhavam um sentido, recebiam voz, ao se juntarem em um único arquivo, no qual ganhavam uma história, um enredo, viriam a ser conhecidas pelo nome de álbuns fotográficos. Sua sobrevivência, tal como sua origem advém de inovações tecnológicas, adaptando-se às mudanças de usos, gosto, mercados, valores e formatos e claro das transformações tecnologias de suporte.

E uma destas adaptações foi a popularização da utilização das imagens no cotidiano da sociedade, em especial no formato de cartão de visita, no qual foram atrelados a um valor simbólico afetivo, e consequentemente, o seu acumulo e guarda gera uma necessidade; um local onde se pudessem arranjar tais imagens. Nessa direção Lima (1993, p.100) assevera que:

O álbum surge, assim, atrelado à idéia de coleção, à prática de acumular objetos revestidos de alto valor afetivo e simbólico. Produzidos inicialmente vazios, à espera do arranjo específico que cada história de vida iria dar aos retratos acumulados, os álbuns não tardaram a se transformar em coleções montadas por um editor, reunindo fotografias de grandes eventos como as exposições universais, 'souvenirs' de viagens e vistas urbanas de lugares exóticos.

A sociedade uma vez atingida pela ideia de consumismo de imagens, não parou mais de estocar as imagens produzidas através da invenção de Joseph Nicéphore Niépce e Louis J. M. Daguerre. Em especial o "cartão de visita", que divulgava uma imagem construída de si, e era oferecida como lembrança, trocada entre parentes e amigos, namorados, e em seguida arquivados nos álbuns.

O álbum fotográfico se revela como um empenho, uma vontade de um grupo particular ou público, em arranjar suas memórias de forma a ter uma leitura direcionada e homogênea do passado. São fotografias e momentos, previamente selecionados, de alto apego afetivo e simbólico que formam uma unidade.

Formando uma narrativa que têm como principal base à ordenação cronológica das fotografias e a relação destas com outros elementos, tais como: legendas, convites de baile, bilhetes e recados, postais, bilhetes de boas festas, molduras, selos, cartões de visita, passagens, convites de casamento, recortes de revistas, jornais, mechas de cabelos, ingressos, pulseira de identificação de maternidade entre outros. Silva (2008, p.18), ao estudar álbuns de famílias colombianas analisa a composição dos álbuns como:

[...] o álbum conta histórias, mas não somente sobre fotos, pois a ele são acrescentados outros objetos: cartões, lembretes, recortes de jornal, relíquias e partes do corpo: umbigos de recém-nascidos, gotas de sangue, mechas de cabelo, unhas de mãos e marcas de pés. Em sentido literal, o álbum é um pedaço de nossos corpos.

Pontuamos que o físico e a sua coerência/ integração organizacional, a união destas características com a parte interna, sua forma de narrativa constituem e se articulam para compor o álbum fotográfico. Dito em outras palavras há de se pensar nas formas que a informação fora registrada neste álbum, de forma interna, suas intenções, 


\section{SEMINÁRIO DE PESQUISA EM CIÊNCIAS HUMANAS - SEPECH \\ Humanidades, Estado e desafios didático-científicos \\ Londrina, 27 a 29 de julho de 2016}

temas, discurso, e de forma externa que se apresenta o físico, em suas composições de materiais e estrutural.

Evidenciamos desta forma, os dois níveis de informação registrada contida no álbum fotográfico: a informação contida em cada documento, como é o caso da fotografia, isoladamente; e as informações contidas no álbum em si, no conjunto, em sua forma, em sua estrutura externa e interna, revelam sobre a instituição ou sobre a pessoa que o criou.

Ao acolher certas técnicas de classificação, este arquivo segue uma racionalidade, uma lógica que nem sempre é perceptível a um olhar mais apressado. A lógica da ordenação dos "saltos" como sita o autor entre as fotografias, nem sempre é cronológico.

Mas há algo inevitável: ele possui uma ordem em que uma foto se encadeia a outra, e, portanto, sua visão produz a figura do "salto"palavra que parece definir bem esse fenômeno - , tendo em vista que "saltar" de uma foto para outra, para recompor um propósito global. Sua nunciação muda, como o teatro, com cada encenação, com a introdução de uma nova foto que transforma a ordem das já existentes. (SILVA, 2008, p.32)

Há casos em que a racionalidade dorme na gênese do álbum fotográfico. Tal fato se deve a função e uso que este recurso ao ser criado margeia. Essa característica do álbum fotográfico de guarda de memória e por consequências construções e silêncios advém do seu possível uso social. Ao adentrar um centro de informação, o cientista necessita observar como já foi dito a gênese deste recurso, pois este é passível de alterações, de novos acréscimos, de retiradas. O que modifica e descontextualiza a construção e a lógica implantada em sua gênese.

Assim, colocamos em evidencia a necessidade de se observar este recurso com um olhar crítico. E ao se deparar com um exemplar deste recurso informacional, nos quais seus componentes não possuem uma racionalidade, não linear, conflituoso e sem um sentido lógico, pontuamos a necessidade imperativa que se busque com afinco a gênese documental para organização e representação do conteúdo do álbum com vistas na sua recuperação e uso, pois a racionalidade estará atrelada a sua gênese, o que trará mais respostas.

\section{A GÊNESE DOCUMENTAL DO ÁLBUM FOTOGRÁFICO NA PERSPECTIVA DA ORGANIZAÇÃO E REPRESENTAÇÃO DA INFORMAÇÃO.}

A organização e a representação são conceitos inerentes ao próprio desenvolvimento da humanidade. A organização está presente em diversas ações da vida em sociedade, como desde a organização sistêmica do funcionamento corpóreo dos seres vivos, que é uma organização natural, até a organização funcional e administrativa de uma instituição, uma entidade ou uma organização.

$\mathrm{Na}$ Ciência da Informação a organização da informação é considerada “[...] um processo que envolve a descrição física e de conteúdo dos objetos informacionais" 


\section{SEMINÁRIO DE PESQUISA EM CIÊNCIAS HUMANAS - SEPECH \\ Humanidades, Estado e desafios didático-científicos \\ Londrina, 27 a 29 de julho de 2016}

(BRASCHER; CAFÉ, 2010, p.5). E a representação da informação o ato de utilização de símbolos ou qualquer elemento significativo que representem uma realidade (ALVARENGA, 2003).

Consideramos o álbum fotográfico como um dossiê que pode reunir documentos de diversas espécies: cartas, fotografias, bilhetes, entre outros. E ainda, a reunião de múltiplos gêneros de documentos: escrito, imagens fixas e até objetos tridimensionais. Sua compreensão deve estar atrelada a intencionalidade particular ou institucional, que o configurou.

Essa intenção na literatura de Ciência da Informação é considerada como a gênese documental, que significa a ação que determinou sua elaboração, ou seja, a relação intrínseca do conteúdo informacional de um documento ou imagem com a objetividade de seu produtor/originador. Essa objetividade ou intenção são fundamentais e determinantes para a efetiva compreensão do documento.

A autora Bellotto (2002, p. 36) discute a gênese dos documentos públicos e aponta que

Todo documento tem um autor ou autores, é dirigido a um indivíduo ou a uma coletividade, sua gê- nese está datada de um lugar (data tópica) e de um tempo (data cronológica) e se produz por alguma razão contida em seu texto [...]. Há condições de aplicação e de sanção que dele também constam.

Antes do ato de registrar uma imagem, a fotografia nasce de uma intencionalidade ou função que determina a iniciativa do seu registro. E é essa intencionalidade que diz respeito a sua gênese, ou seja, a sua produção. No entanto, muitas iniciativas de organização de acervos fotográficos tendem a enfocar o uso imediato de suas imagens em detrimento da sua função primária, a intencionalidade de sua criação.

O tratamento dispensado a documentação fotográfica realizado pela maioria das instituições, que vêm na fotografia apenas seu uso imediato, não se preocupam com a permanência das informações primárias $\mathrm{e}$ originais daquele documento, mas privilegiam a conservação do suporte físico e a difusão dos registros imagéticos em banco de dados informatizados (MADIO; FUJITA, 2008, p. 254).

Considerar a gênese documental na organização e representação de conteúdos imagéticos e na própria configuração de um álbum fotográfico coloca sua lógica construtiva em maior alcance da compreensão de seus significados, pois é a ação original dentro de um contexto institucional que deve determinar o arquivamento dos documentos. Deve-se buscar a "historicidade e o contexto histórico de produção da(s) fotografia(s)". (MADIO; FUJITA, 2008, p. 253).

Assim, para o resgate e preservação da memória histórica do conteúdo compreendido em um álbum fotográfico deve-se partir do contexto de sua ação original, pela qual sua organização, tratamento e representação poderá garantir maior qualidade informativa. 


\section{SEMINÁRIO DE PESQUISA EM CIÊNCIAS HUMANAS - SEPECH \\ Humanidades, Estado e desafios didático-científicos \\ Londrina, 27 a 29 de julho de 2016}

\section{CONSIDERAÇÕES PARCIAIS}

A pesquisa encontra-se na fase de revisão e discussão da bibliografia da área de Organização e Representação da Informação e foi possível perceber a dificuldade de encontrar literatura que aborde a gênese documental do álbum fotográfico. O que mais encontramos no contexto da Ciência da Informação foram abordagens acerca da organização e tratamento da fotografia. A organização e representação de álbuns fotográficos atrelados à sua gênese documental ainda carece de estudos e reflexões.

O levantamento da bibliografia referente à gênese documental do álbum fotográfico foi realizado, num primeiro momento, nos Anais dos Encontros Nacional de Pesquisa e Pós-Graduação em Ciência da Informação, promovidos pela Associação Nacional de Pesquisa e Pós-Graduação em Ciência da Informação, que é uma sociedade civil, sem fins lucrativos, fundada em junho de 1989, cuja finalidade é acompanhar e estimular as atividades de ensino de pós-graduação e de pesquisa em Ciência da Informação no Brasil. Foi identificado, em 15 encontros, um total de 41 trabalhos referente à fotografia. Destes, apenas um se refere a gênese documental para organização e representação da informação de fotografias.

$\mathrm{Na}$ próxima etapa da pesquisa, pretende-se a partir da bibliografia em Organização e Representação da Informação levantar o embasamento teórico para o constructo da organização e representação da informação de álbuns fotográficos atrelados a sua gênese documental.

\section{REFERÊNCIAS}

ALVARENGA, L. Representação do conhecimento na perspectiva da ciência da informação em tempo e espaço digitais. Encontros Bibli: Revista Eletrônica de Biblioteconomia e Ciência da Informação, Florianópolis, n. 15, jan./jun. 2003.

BELlOTTO, H. L. (2002) Como fazer análise diplomática e análise tipológica de documento de arquivo. São Paulo: Arquivo do Estado, Imprensa Oficial do Estado, 2002 .

BRASCHER, M.; CAFÉ, L. Organização da Informação ou Organização do Conhecimento?. In: LARA, M. G. de; SMIT, J. W. (Orgs.). Temas de pesquisa em Ciência da Informação no Brasil. São Paulo: Escola de Comunicação e Artes da Universidade de São Paulo. 2010. Disponível em: $<$ http://www.pos.eca.usp.br/sites/default/files/enancibdigital.pdf $>$. Acesso em $07 \mathrm{de}$ mar. 2016.

LIMA, S. F. de. Espaços projetados: as representações da cidade de São Paulo nos álbuns fotográficos do inicio do século. Acervo Revista do Arquivo Nacional, Rio de Janeiro, v.6, n.1-2, p. 99-110, jan./dez. 1993.

LIMA, J. L. O.; ALVARES, L. Organização e representação da informação e do conhecimento. In: ALVARES, L. (Org.). Organização da informação e do 


\section{SEMINÁRIO DE PESQUISA EM CIÊNCIAS HUMANAS - SEPECH \\ Humanidades, Estado e desafios didático-científicos \\ Londrina, 27 a 29 de julho de 2016}

conhecimento: conceitos, subsídios interdisciplinares e aplicações. São Paulo: B4 Editores, 2012. 248p. Capítulo 1, p. 21/48.

LOPEZ, A. P. A. As razões e os sentidos: finalidades da produção documental e interpretação de conteúdos na organização arquivística de documentos imagéticos. Tese de Doutoramento. 2000. Tese (Doutorado em História Social da FFLCH/USP, 2000).

MADIO, T. C. C.; FUJITA, M. S. L. Importancia de la génesis documental para identificación de acervos fotograficos. Ibersid, v. 2, p. 251-261, 2008. Disponível em: < file://C:/Users/lidiane.freitas/Downloads/2244-2254-1-PB\%20(2).pdf>. Acesso em: 18 abr. 2016.

SILVA, A. Álbum de família: a imagem de nós mesmos. São Paulo: Senac, 2008.

SOUGEZ, M. História da fotografia. Lisboa: Ediciones Cátedra, 2001. 